\title{
Chronic kidney disease in US adults with type 2 diabetes: an updated national estimate of prevalence based on Kidney Disease: Improving Global Outcomes (KDIGO) staging
}

Robert A Bailey ${ }^{1 *}$, Yiting Wang ${ }^{2}$, Vivienne Zhu $^{2}$ and Marcia FT Rupnow ${ }^{1}$

\begin{abstract}
Background: Kidney Disease Improving Global Outcomes (KDIGO) 2013 updated the classification and risk stratification of chronic kidney disease (CKD) to include both the level of renal function and urinary albumin excretion (UAE). The update subclassifies the previous category of moderate renal impairment. There is currently limited information on the prevalence of CKD based on this new classification in United States (US) adults with type 2 diabetes mellitus (T2DM). The objective of this study was to provide such estimates, for T2DM both overall and in those $\geq 65$ years of age. We used the continuous National Health and Nutrition Examination Survey (NHANES) 1999-2012 to identify participants with T2DM. Estimated glomerular filtration rate (eGFR) and UAE were calculated using laboratory results and data collected from the surveys, and categorized based on the KDIGO classification. Projections for the US T2DM population were based on NHANES sampling weights.
\end{abstract}

Results: A total of 2915 adults diagnosed with T2DM were identified from NHANES, with 1466 being age $\geq 65$ years. Prevalence of CKD based on either eGFR or UAE was $43.5 \%$ in the T2DM population overall, and $61.0 \%$ in those age $\geq 65$ years. The prevalence of mildly decreased renal function or worse (eGFR $\left.<60 / \mathrm{ml} / \mathrm{min} / 1.73 \mathrm{~m}^{2}\right)$ was $22.0 \%$ overall and $43.1 \%$ in those age $\geq 65$ years. Prevalence of more severe renal impairment $\left(e G F R<45 \mathrm{ml} / \mathrm{min} / 1.73 \mathrm{~m}^{2}\right.$ ) was $9.0 \%$ overall and $18.6 \%$ in those age $\geq 65$ years. The prevalence of elevated UAE ( $>30 \mathrm{mg} / \mathrm{g}$ ) was $32.2 \%$ overall and $39.1 \%$ in those age $\geq 65$ years. The most common comorbidities were hypertension, retinopathy, coronary heart disease, myocardial infarction, and congestive heart failure.

Conclusions: This study confirms the high prevalence of CKD in T2DM, impacting 43.5\% of this population. Additionally, this study is among the first to report US prevalence estimates of CKD based on the new KDIGO CKD staging system.

Keywords: Diabetes, Type 2 diabetes mellitus, Chronic kidney disease, Prevalence, Estimated glomerular filtration rate, Albuminuria

\section{Background}

Type 2 diabetes mellitus (T2DM) is the leading cause of chronic kidney disease (CKD) in the United States (US), with previous estimates suggesting close to $40 \%$ of patients with T2DM having evidence of CKD [1]. Concordant with the high prevalence of CKD in this population, diabetes was attributed as the cause of end-stage renal disease (ESRD) in $44.2 \%$ of incident dialysis patients in 2011 [2].

\footnotetext{
* Correspondence: rbailey5@its.jnj.com

'Janssen Scientific Affairs, LLC, 1000 Route 202 South, Raritan, NJ 08869, USA Full list of author information is available at the end of the article
}

The high burden of CKD in T2DM and the associated adverse outcomes result in high health-care costs to both public and private payers $[2,3]$.

Based on the significant impact of CKD, Kidney Disease Outcomes Quality Initiative (KDOQI) and Kidney Disease: Improving Global Outcomes (KDIGO) recommend a focus on early identification of CKD. This early identification may allow for treatment directed at CKD to slow or prevent progression, and treatment of associated complications and comorbidities such as cardiovascular disease $[4,5]$. 
KDOQI originally proposed a uniform CKD staging and classification system based on estimated glomerular filtration rate (eGFR) [5]. The original classification ranged from Stage 1 CKD (defined as normal kidney function with other markers for kidney damage) to Stage 5 CKD (defined as kidney failure). This staging system served to provide clinicians with stage-specific action plans for treatment of CKD and associated comorbidities and complications. Additionally, this staging system facilitated research and served as a framework for developing a public-health approach to CKD.

Soon after the original KDOQI CKD staging system was published, Go et al. [6] reported that although the risk for death, cardiovascular disease, and hospitalizations increased when eGFR declined below $60 \mathrm{ml} / \mathrm{min} / 1.73 \mathrm{~m}^{2}$ (Stage $3 \mathrm{CKD}$ ), these risks substantially increased when eGFR declined below $45 \mathrm{ml} / \mathrm{min} / 1.73 \mathrm{~m}^{2}$ [6]. Based on this evidence, Go et al. advocated for subclassification of Stage 3 to reflect these findings. A recent meta-analysis provided further evidence to support the division of Stage $3 \mathrm{CKD}$ into $3 \mathrm{a}$ and $3 \mathrm{~b}$ based on the increased risk for progression to ESRD, and cardiovascular and all-cause mortality at the GFR threshold of $<45 \mathrm{ml} / \mathrm{min} / \mathrm{m}^{2}[7,8]$.

Based on this new evidence, developed since KDOQI, KDIGO recently updated the classification system for CKD [4]. This new classification system is based on the cause of CKD, gFR category, and albuminuria category (CGA). The cause category is based on the presence or absence of systemic disease. The GFR categories acknowledge the need to subdivide Stage 3 CKD, classified as G3 under the new classification system, into G3a (eGFR 4559) and G3b (eGFR 30-44). The albuminuria categories are based on the presence and severity of albuminuria. This new classification was developed to allow risk stratification based on progression of CKD and cardiovascular and all-cause mortality.

The prevalence of diabetes in the older adult population (age $>65$ ) is greater than 20\%. This older adult group also has a higher prevalence of comorbid conditions (such hypertension, cardiovascular disease, and CKD) compared to younger populations $[2,9]$. Based on these specific considerations in the older adult population, the American Diabetes Association (ADA) recommends a different approach in this population. These specific recommendations include potentially less stringent treatment targets and special consideration in the selection of antihyperglycemic agents.

To date, there are no US estimates of the prevalence of CKD in T2DM based on this new classification system, particularly for stages G3a and G3b. The objective of this study was to provide current national estimates of the prevalence of CKD in the overall T2DM population, and in the subpopulation aged $\geq 65$ years using this new KDIGO classification.

\section{Methods}

National Health and Nutrition Examination Survey (NHANES) 1999-2012 data were used for this study. NHANES is a cross-sectional survey designed to monitor the health and nutritional status of the civilian noninstitutionalized US population [10]. NHANES data include demographics, comorbidities, and medications that were reported by the survey participants during a home interview. Additionally, standardized physical examinations and laboratory tests were conducted in mobile examination centers. This study was exempt from the requirement of an Institutional Review Board since this research was based on data that were available from a publicly available source.

NHANES participants with T2DM were identified using previously published criteria to differentiate T2DM from type 1 diabetes mellitus (T1DM) [11,12]. The criteria used were: self-reported diagnosis of diabetes or "sugar diabetes" at age $\geq 30$ years, not initiating insulin therapy within 1 year of diagnosis, and not pregnant (women) at the time of interview and examination. We focused on diagnosed diabetes with an aim to help health-care providers and population health managers to understand CKD and plan preventive management for their patients known to have T2DM; strategies for prediabetes and undiagnosed diabetes (such as by the criteria of hemoglobin A1c above 6.5\% or single fasting plasma glucose measure above $180 \mathrm{mg} / \mathrm{dl}$ ) are likely to be different. Since evidence suggests that the prevalence of reduced GFR, albuminuria, and micro/ macrovascular complications differs between T1DM and T2DM [13], we made an effort to identify and exclude those with T1DM.

Comorbidities were determined based on participant self-reporting of diagnosis by a doctor or other health-care professional. The identification of hypertension was additionally based on measured mean systolic blood pressure/ diastolic blood pressure $>140 / 90 \mathrm{mmHg}$, or self-reported use of antihypertensive agents, including diuretics, betablockers, calcium-channel blockers, angiotensin-converting enzyme (ACE) inhibitors, angiotensin receptor blockers, or other antihypertensive agents (including alpha-1-blockers, central alpha-2-agonists, direct vasodilators, renin inhibitors, and other centrally acting drugs).

To ensure comparability with standard lab assays and consistency when testing methods or instruments change across different survey cycles, NHANES conducts quality assurance and monitoring, and provides specific calibration recommendations in analytical notes for affected lab tests and survey cycles [10]. Serum creatinine levels measured from the 1999-2000, and 2005-2006 survey cycles were calibrated according to NHANES recommended equations to be traceable to an isotope dilution mass spectrometry (IDMS) reference method (calibration not needed for the other survey years in this study). Similarly, urine creatinine measures before the 2007-2008 surveys were corrected 
according to NHANES recommendations to be consistent with the 2007-2008 survey and forward. Spot urine albumin was measured and tested consistently across 19992012 survey cycles. Urinary albumin to creatinine ratio (UACR) was calculated by taking the ratio between urinary albumin and urinary creatinine and expressed as $\mathrm{mg} / \mathrm{g}$ [14].

CKD was categorized based on the new KDIGO classification recommendations [4]. GFR categories were based on eGFR: G1 $\geq 90 \mathrm{ml} / \mathrm{min} / 1.73 \mathrm{~m}^{2}$ (normal to high), G2 $60-89 \mathrm{ml} / \mathrm{min} / 1.73 \mathrm{~m}^{2}$ (mildly decreased), G3a $45-59 \mathrm{ml} /$ $\min / 1.73 \mathrm{~m}^{2}$ (mildly to moderately decreased), G3b 30$44 \mathrm{ml} / \mathrm{min} / 1.73 \mathrm{~m}^{2}$ (moderately to severely decreased), G4 $15-29 \mathrm{ml} / \mathrm{min} / 1.73 \mathrm{~m}^{2}$ (severely decreased), and G5< $15 \mathrm{ml} / \mathrm{min} / 1.73 \mathrm{~m}^{2}$ (kidney failure). Albuminuria categories were based on the UACR: A1 $<30 \mathrm{mg} / \mathrm{g}$ (normal to mildly increased), A2 $30-300 \quad \mathrm{mg} / \mathrm{g}$ (moderately increased), and A3 > $300 \mathrm{mg} / \mathrm{g}$ (severely increased). eGFR was calculated using the Chronic Kidney Disease Epidemiology Collaboration (CKD-EPI) equation [14]. Because some practitioners and institutions may still use the Modification of Diet in Renal Disease (MDRD) equation [15], eGFR using this equation was also calculated and reported.

To provide an estimate of the US prevalence of CKD in the overall and age $\geq 65$ years T2DM population, the observations from the NHANES were weighted to account for the complex design of NHANES [16] and age-adjusted to the 2012 US diabetes population according to the National Health Interview Survey (NHIS) $[17,18]$. Statistical analyses were performed using survey procedures in SAS version 9.2 (SAS Institute, Cary, North Carolina, USA). We performed linear trend tests on the projected mean eGFR and UACR values, as well as prevalence of the eGFR and UACR categories by the KDIGO classification. Two-sided $\mathrm{p}$ values of $<0.05$ were considered statistically significant.

\section{Results}

A total of 2915 adults with T2DM were identified from NHANES 1999-2012. We combined the NHANES 19992012 data because none of the linear trend tests for eGFR and UACR were statistically significant, and numerical values also appeared comparable across these survey cycles (data not shown). The sample demographics and projected national estimates are presented in Table 1. Based on the national estimates, the mean standard error (SE) age of the US T2DM population was 61.4 (0.4) years, with 50.3\% age $\geq$ 65 years. The mean (SE) duration of T2DM was $9.7(0.1)$ years. Non-Hispanic whites comprised $62.6 \%$ of the study population, non-Hispanic blacks $15.9 \%$, and Mexican Americans $8.1 \%$. The most common self-reported comorbidities were hypertension (71.9\%), retinopathy (20.9\%), coronary heart disease (12.5\%), myocardial infarction $(12.0 \%)$, and congestive heart failure (10.6\%).
The national estimate of mean (SE) eGFR (CKD-EPI) for the T2DM population was $80.5(0.5) \mathrm{ml} / \mathrm{min} / 1.73 \mathrm{~m}^{2}$, and the mean (SE) urinary albumin excretion (UAE) was 109.1 (1.4) $\mathrm{mg} / \mathrm{g}$. The overall prevalence of CKD based on either eGFR (CKD-EPI) or albuminuria criteria was $43.5 \%$, with 95\% confidence interval (CI) 41.6-45.4\%. The prevalence of mildly decreased to more severe renal impairment based on eGFR below the threshold of $60 \mathrm{ml} / \mathrm{min} / 1.73 \mathrm{~m}^{2}$ was $22 \%$ (95\% CI 20.4-23.5\%). Based on the new subdivision of stage 3 CKD into $3 \mathrm{a} / 3 \mathrm{~b}$, the prevalence of Stage 3a CKD (eGFR > 45-59 ml/min/1.73 m²) was $12.9 \%$ (95\% CI 11.5 14.3\%) (Table 2) and Stage 3b or lower (eGFR $<45 \mathrm{ml} / \mathrm{min} /$ $1.73 \mathrm{~m}^{2}$ ) was $9 \%(95 \%$ CI $7.8-10.3 \%)$. The prevalence of elevated UAE based on UACR $\geq 30 \mathrm{mg} / \mathrm{g}$ was $32.2 \%$ (95\% CI 30.0-34.3\%), 24.4\% (95\% CI 22.3-26.4\%) with moderately increased (UACR $\geq 30-300 \mathrm{mg} / \mathrm{g}$ ) and $7.8 \%$ (95\% CI 6.59.1\%) with severely increased (UACR $>300 \mathrm{mg} / \mathrm{g}$ ) UAE.

Using MDRD to calculate eGFR, the mean (SE) eGFR was $79.1(0.6) \mathrm{ml} / \mathrm{min} / 1.73 \mathrm{~m}^{2}$. The overall prevalence of CKD using either eGFR (MDRD) or albuminuria criteria was $45.1 \%$, 95\% CI $43.0-47.1 \%$. The prevalence of mildly decreased to more severe renal impairment based on eGFR below the threshold of $60 \mathrm{ml} / \mathrm{min} / 1.73 \mathrm{~m}^{2}$ was 24.0\%, 95\% CI 22.1-26.0\%; 14.9\% (95\% CI 13.2-16.6\%) had eGFR (MDRD) $45-59 \mathrm{ml} / \mathrm{min} / 1.73 \mathrm{~m}^{2}$ (Table 3) and $9.2 \%$ had eGFR (MDRD) $<45 \mathrm{ml} / \mathrm{min} / 1.73 \mathrm{~m}^{2}$.

A total of 1466 NHANES participants were aged $\geq$ 65 years, representing $50.3 \%$ of the analysis sample. The projected mean (SE) age for this population was $73.4(0.1)$ years, and the mean (SE) diabetes duration was $12.9(0.3)$ years. Non-Hispanic whites comprised $72.6 \%$ of the study population age $\geq 65$ years, non-Hispanic blacks $12.4 \%$, and Mexican Americans 5.0\%. The most common self-reported comorbidities were hypertension (80.9\%), retinopathy (22.2\%), coronary heart disease (19.9\%), myocardial infarction (18.2\%), and congestive heart failure (16.9\%).

For the age $\geq 65$ years subgroup, the prevalence of CKD using either eGFR (CKD-EPI) or albuminuria criteria was 61.0\%, 95\% CI (57.9- 64.1\%). The prevalence of mildly decreased to more severe renal impairment based on eGFR (CKD-EPI) below the threshold of $60 \mathrm{ml} / \mathrm{min} / 1.73 \mathrm{~m}^{2}$ was 43.1\% (95\% CI 39.5-46.6\%). Stage G3a (eGFR 45-59 ml/ $\mathrm{min} / 1.73 \mathrm{~m}^{2}$ ) represented $24.5 \%$ (95\% CI 21.6-27.4\%) (Table 4), and eGFR $<45 \mathrm{ml} / \mathrm{min} / 1.73 \mathrm{~m}^{2}$ was $18.6 \%$ (95\% CI 15.9-21.2\%). The prevalence of increased UAE based on $\mathrm{UACR} \geq 30 \mathrm{mg} / \mathrm{g}$ was $39.1 \%$ (95\% CI 36.3-41.8\%). Moderately increased UAE (ACR $30-300 \mathrm{mg} / \mathrm{g}$ ) was present in 29.3\% (95\% CI 26.4-32.2\%), and severely increased UAE (ACR > $300 \mathrm{mg} / \mathrm{g}$ ) was present in 9.8\% (95\% CI 7.5-12.0\%).

Using MDRD to calculate eGFR in the age $\geq 65$ years subgroup, the mean (SE) eGFR was $64.8(0.8) \mathrm{ml} / \mathrm{min} /$ $1.73 \mathrm{~m}^{2}$. The overall prevalence of CKD using either eGFR (MDRD) or albuminuria criteria was $61.8 \%$ (95\% CI 58.5$65.0 \%$ ). The prevalence of mildly decreased to more severe 
Table 1 Demographic characteristics

\begin{tabular}{|c|c|c|c|c|}
\hline \multirow[t]{3}{*}{ Variable } & \multicolumn{2}{|r|}{ Overall } & \multicolumn{2}{|r|}{ Age $\geq 65$ years } \\
\hline & NHANES & \multirow[t]{2}{*}{ Projected national estimate } & NHANES & \multirow[t]{2}{*}{ Projected national estimate } \\
\hline & $N=2915$ & & $N=1466$ & \\
\hline Mean (SE) age, years & $63.9(0.2)$ & $61.4(0.4)$ & $73.4(0.1)$ & $73.1(0.1)$ \\
\hline Age $\geq 65$ years, $\%(n)$ & $50.3(1466)$ & $40.3(\mathrm{~N} / \mathrm{A})$ & $100(1466)$ & $100(N / A)$ \\
\hline Sex, \% male $(n)$ & $52.0(1517)$ & $50.8(\mathrm{~N} / \mathrm{A})$ & $51.8(760)$ & $47.1(\mathrm{~N} / \mathrm{A})$ \\
\hline Mean (SE) diabetes duration, years & $10.7(0.2)$ & $9.7(0.2)$ & $13.2(0.3)$ & $12.9(0.3)$ \\
\hline Mean (SE) eGFR (CKD-EPI), ml/min/1.73 $\mathrm{m}^{2}$ & $78.2(0.5)$ & $80.5(0.5)$ & $65.3(0.6)$ & $64.2(0.8)$ \\
\hline Mean (SE) eGFR (MDRD), $\mathrm{ml} / \mathrm{min} / 1.73 \mathrm{~m}^{2}$ & $78.5(0.5)$ & $79.1(0.6)$ & $66.7(0.6)$ & $64.8(0.8)$ \\
\hline Mean (SE) UAE, mg/g & $109.7(1.3)$ & $109.1(1.4)$ & $103.4(1.6)$ & $99.1(1.8)$ \\
\hline \multicolumn{5}{|l|}{ Race/ethnicity } \\
\hline Mexican American, \% (n) & $21.9(638)$ & $8.1(\mathrm{~N} / \mathrm{A})$ & $18.4(269)$ & $5.0\left(N / A^{a}\right)$ \\
\hline Other Hispanic, \% (n) & $7.9(231)$ & $5.9(\mathrm{~N} / \mathrm{A})$ & $6.0(88)$ & $3.4\left(N / A^{a}\right)$ \\
\hline Non-Hispanic white, \% (n) & $37.9(1105)$ & $62.6(N / A)$ & $47.0(689)$ & $72.6\left(N / A^{a}\right)$ \\
\hline Non-Hispanic black, \% (n) & $26.5(773)$ & $15.9(\mathrm{~N} / \mathrm{A})$ & $23.1(338)$ & $12.4\left(N / A^{a}\right)$ \\
\hline Other, including multiracial, \% (n) & $5.8(168)$ & $7.4(\mathrm{~N} / \mathrm{A})$ & $5.6(82)$ & $6.5\left(N / A^{a}\right)$ \\
\hline \multicolumn{5}{|l|}{ Comorbidities (self-reported) } \\
\hline Hypertension, \% (n) ${ }^{a}$ & $74.0(2157)$ & 71.9 (N/A) & $80.3(1177)$ & $80.9\left(N / A^{a}\right)$ \\
\hline Retinopathy, \% (n) & $22.1(645)$ & 20.9 (N/A) & $23.1(339)$ & $22.2\left(N / A^{a}\right)$ \\
\hline Coronary heart disease, \% (n) & $12.0(351)$ & $12.5(\mathrm{~N} / \mathrm{A})$ & $16.6(243)$ & $19.9\left(\mathrm{~N} / \mathrm{A}^{\mathrm{a}}\right)$ \\
\hline Myocardial infarction, \% (n) & $12.7(371)$ & $12.0(\mathrm{~N} / \mathrm{A})$ & $16.5(241)$ & $18.2\left(N / A^{a}\right)$ \\
\hline Congestive heart failure, \% (n) & $11.2(326)$ & $10.6(\mathrm{~N} / \mathrm{A})$ & $15.5(227)$ & $16.9\left(N / A^{a}\right)$ \\
\hline Angina, \% (n) & $9.0(261)$ & $9.5(\mathrm{~N} / \mathrm{A})$ & $11.4(167)$ & $13.9\left(\mathrm{~N} / \mathrm{A}^{\mathrm{a}}\right)$ \\
\hline Stroke, \% (n) & $10.1(293)$ & 9.1 (N/A) & $13.6(200)$ & $14.4\left(N / A^{a}\right)$ \\
\hline
\end{tabular}

${ }^{a} \mathrm{~N}=21,318,626$ based on the total number of persons with diabetes who were age $\geq 18$ years, NHIS 2012.

renal impairment based on eGFR (MDRD) below the threshold of $60 \mathrm{ml} / \mathrm{min} / 1.73 \mathrm{~m}^{2}$ was $44.2 \%$ (95\% CI 40.348.1\%); $26.1 \%$ had eGFR $45-59 \mathrm{ml} / \mathrm{min} / 1.73 \mathrm{~m}^{2}$ (95\% CI 22.9-29.3\%) (Table 5), and 18.1\% (95\% CI 15.5-20.8\%) had eGFR $<45 \mathrm{ml} / \mathrm{min} / 1.73 \mathrm{~m}^{2}$.

\section{Discussion}

Based on a nationally representative sample, this report is the first to provide estimates of the prevalence of CKD in the US population with T2DM based on the new KDIGO classification. These new estimates provide insights on the

Table 2 eGFR (CKD-EPI) and UACR category prevalence of CKD in T2DM ${ }^{a}$

\begin{tabular}{|c|c|c|c|c|c|c|c|c|}
\hline \multirow{3}{*}{$\begin{array}{l}\text { GFR category, } \\
\mathrm{ml} / \mathrm{min} / 1.73 \mathrm{~m}^{2} \text { (CKD-EPI) }\end{array}$} & \multicolumn{8}{|c|}{ Albuminuria category, $\mathrm{mg} / \mathrm{g}$} \\
\hline & \multicolumn{2}{|r|}{$<30$} & \multicolumn{2}{|r|}{$30-300$} & \multicolumn{2}{|c|}{$>300$} & \multicolumn{2}{|r|}{ Row $^{c}$} \\
\hline & $\mathrm{N}$ & $\%(95 \% \mathrm{Cl})$ & $N$ & $\%(95 \% \mathrm{Cl})$ & $\mathrm{N}$ & $\%(95 \% \mathrm{Cl})$ & $\mathrm{N}$ & $\%(95 \% \mathrm{Cl})$ \\
\hline $\mathrm{G1} \geq 90$ & $733^{b}$ & $29.1(27.0-31.2)$ & 269 & $9.2(7.8-10.5)$ & 56 & $1.4(0.9-1.9)$ & 1058 & $39.7(37.4-42.0)$ \\
\hline G2 60-89 & $753^{b}$ & $27.4(25.1-29.6)$ & 282 & $8.4(7.0-9.7)$ & 92 & $2.6(1.9-3.2)$ & 1127 & $38.3(35.7-40.9)$ \\
\hline G3a 45-59 & 242 & $8.0(6.9-9.2)$ & 132 & $3.6(2.8-4.3)$ & 49 & $1.4(0.8-1.9)$ & 423 & $12.9(11.5-14.3)$ \\
\hline G3b 30-44 & 84 & $2.7(2.1-3.3)$ & 75 & $2.1(1.5-2.6)$ & 36 & $1.0(0.5-1.5)$ & 195 & $5.8(4.8-6.8)$ \\
\hline G4 15-29 & 20 & $0.6(0.2-0.9)$ & 33 & $1.2(0.6-1.7)$ & 36 & $1.0(0.5-1.6)$ & 89 & $2.8(2.0-3.6)$ \\
\hline G5 $<15$ & d & $0.0(0.0-0.1)$ & d & $0.0(0.0-0.0)$ & 20 & $0.4(0.1-0.6)$ & 23 & $0.4(0.2-0.7)$ \\
\hline Column N, \% $(95 \% \mathrm{Cl})^{c}$ & 1834 & $67.8(65.7-70.0)$ & 792 & $24.4(22.3-26.4)$ & 289 & $7.8(6.5-9.1)$ & 2915 & $100(\mathrm{~N} / \mathrm{A})$ \\
\hline
\end{tabular}

${ }^{a}$ Age adjusted to 2012 NHIS diabetes population.

boes not meet CKD criteria based on eGFR or albuminuria.

'Sum of rows and columns may deviate due to rounding.

${ }^{d}$ Cell frequency suppressed when count $<3$ to avoid potential identifiability and imprecision of estimates. 
Table 3 eGFR (MDRD) and UACR category prevalence of CKD in T2DM ${ }^{\mathrm{a}}$

\begin{tabular}{|c|c|c|c|c|c|c|c|c|}
\hline \multirow{3}{*}{$\begin{array}{l}\text { GFR category, } \\
\mathrm{ml} / \mathrm{min} / 1.73 \mathrm{~m}^{2} \text { (MDRD) }\end{array}$} & \multicolumn{8}{|c|}{ Albuminuria category, $\mathrm{mg} / \mathrm{g}$} \\
\hline & \multicolumn{2}{|r|}{$<30$} & \multicolumn{2}{|r|}{$30-300$} & \multicolumn{2}{|c|}{$>300$} & \multicolumn{2}{|r|}{ Row $^{c}$} \\
\hline & $\mathrm{N}$ & $\%(95 \% \mathrm{Cl})$ & $\mathrm{N}$ & $\%(95 \% \mathrm{Cl})$ & $\mathrm{N}$ & $\%(95 \% \mathrm{Cl})$ & $\mathrm{N}$ & $\%(95 \% \mathrm{Cl})$ \\
\hline $\mathrm{G1} \geq 90$ & $629^{b}$ & $22.9(20.7-25.1)$ & 239 & $7.4(6.1-8.6)$ & 46 & $1.2(0.7-1.7)$ & 914 & $31.4(28.9-34.0)$ \\
\hline G2 60-89 & $834^{\mathrm{b}}$ & $32.1(29.4-34.7)$ & 305 & $9.8(8.3-11.3)$ & 97 & $2.7(2.0-3.3)$ & 1236 & $44.6(41.7-47.5)$ \\
\hline G3a 45-59 & 267 & $9.6(8.2-11.0)$ & 141 & $4.0(3.0-4.9)$ & 51 & $1.4(0.8-1.9)$ & 459 & $14.9(13.2-16.6)$ \\
\hline G3b 30-44 & 88 & $2.9(2.2-3.7)$ & 74 & $2.1(1.5-2.6)$ & 40 & $1.2(0.7-1.7)$ & 202 & $6.2(5.1-7.2)$ \\
\hline G4 15-29 & 15 & $0.4(0.2-0.5)$ & 32 & $1.2(0.6-1.7)$ & 35 & $1.0(0.4-1.6)$ & 82 & $2.5(1.8-3.2)$ \\
\hline G5 $<15$ & d & $0.0(0.0-0.0)$ & d & $0.0(0.0-0.0)$ & 20 & $0.4(0.1-0.6)$ & 22 & $0.5(0.1-0.7)$ \\
\hline Column N, \% $(95 \% \mathrm{CI})^{c}$ & 1834 & $67.8(65.7-70.0)$ & 792 & $24.4(22.3-26.4)$ & 289 & $7.8(6.5-9.1)$ & 2915 & $100(\mathrm{~N} / \mathrm{A})$ \\
\hline
\end{tabular}

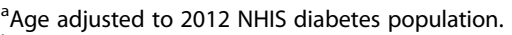

${ }^{b}$ Does not meet CKD criteria based on eGFR or albuminuria.

c Sum of rows and columns may deviate due to rounding.

${ }^{d}$ Cell frequency suppressed when count $<3$ to avoid potential identifiability and imprecision of estimates.

prevalence of the GFR categories G3a and G3b and the albuminuria categories. A recent report by Plantinga et al. [19] using NHANES 1999-2006 and a similar staging of CKD reported a slightly lower prevalence of CKD than this study. The Plantinga et al. report was based on a smaller sample size (the more recent NHANES data were not available at the time of their study) with a lower mean age, and did not attempt to exclude T1DM or those diagnosed with T2DM age $<30$ years. A previous report by Coresh et al. [20] observed that the prevalence of CKD increased with age, suggesting that the criteria used for this study may explain some of the differences observed. Additionally, the previous report did not provide the distribution of albuminuria categories as it predated the new KDIGO classification.

Another recent report on the prevalence of CKD in diabetes based on NHANES 2005-2010 observed a lower prevalence of CKD [2]. This analysis included both T1DM and T2DM, and included NHANES participants age $\geq$ 20 years, which may explain the differences in CKD prevalence observations. Additionally, the analysis did not report details regarding the severity of albuminuria.

Consistent with previous reports, the overall prevalence of CKD based on eGFR was lower using CKD-EPI compared to MDRD [21,22]. Based on the evidence that CKD-EPI is more accurate than MDRD for estimating kidney function and predicting risk of mortality and ESRD (KDIGO), CKD-EPI is now the recommended equation. We chose to report eGFR based on MDRD as well, as this equation may still be in use by some clinicians and institutions [23].

The prevalence of CKD in the age $\geq 65$ years population was higher than in the overall T2DM population. This is consistent with previous reports of increasing prevalence of CKD [20] and incidence of ESRD [24] with age. The prevalence of comorbidities such as hypertension, retinopathy, and cardiac disease was higher in the age $\geq 65$ years population compared to the overall population.

The recognition of the presence of CKD and classification based on the severity of CKD was first proposed by

Table 4 Age $\geq 65$ years: eGFR (CKD-EPI) and ACR category prevalence of CKD in T2DM ${ }^{a}$

\begin{tabular}{|c|c|c|c|c|c|c|c|c|}
\hline \multirow{3}{*}{$\begin{array}{l}\text { GFR category, } \\
\mathrm{ml} / \mathrm{min} / 1.73 \mathrm{~m}^{2} \text { (CKD-EPI) }\end{array}$} & \multicolumn{8}{|c|}{ Albuminuria category, $\mathrm{mg} / \mathrm{g}$} \\
\hline & \multicolumn{2}{|r|}{$<30$} & \multicolumn{2}{|r|}{$30-300$} & \multicolumn{2}{|c|}{$>300$} & \multicolumn{2}{|r|}{ Row $^{c}$} \\
\hline & $\mathrm{N}$ & $\%(95 \% \mathrm{Cl})$ & $\mathbf{N}$ & $\%(95 \% \mathrm{Cl})$ & $\mathrm{N}$ & $\%(95 \% \mathrm{Cl})$ & $\mathrm{N}$ & $\%(95 \% \mathrm{Cl})$ \\
\hline $\mathrm{G} 1 \geq 90$ & $120^{\mathrm{b}}$ & $6.0(4.7-7.3)$ & 54 & $3.2(2.2-4.1)$ & 7 & $0.2(0.0-0.3)$ & 181 & $9.4(7.9-10.9)$ \\
\hline G2 60-89 & $448^{\mathrm{b}}$ & $33.0(30.3-35.8)$ & 187 & $11.5(9.5-13.6)$ & 51 & $3.1(2.0-4.1)$ & 686 & $47.6(44.4-50.8)$ \\
\hline G3a 45-59 & 197 & $14.8(12.6-17.0)$ & 111 & $7.5(5.9-9.2)$ & 35 & $2.2(1.2-3.2)$ & 343 & $24.5(21.6-27.4)$ \\
\hline G3b 30-44 & 69 & $5.6(4.2 \%-7.0)$ & 68 & $4.4(3.2-5.7)$ & 31 & $2.1(1.0-3.3)$ & 168 & $12.2(10.0-14.4)$ \\
\hline G4 15-29 & 19 & $1.4(0.6-2.2)$ & 28 & $2.7(1.4-4.0)$ & 29 & $2.0(0.9-3.1)$ & 76 & $6.1(4.5-7.8)$ \\
\hline $\mathrm{G} 5<15$ & $d$ & $0.1(-0.1-0.2)$ & $d$ & $0.0(0.0-0.0)$ & 10 & $0.2(0.0-0.4)$ & 12 & $0.3(0.1-0.5)$ \\
\hline Column N, \% $(95 \% \mathrm{Cl})^{c}$ & 854 & $60.9(58.2-63.7)$ & 449 & $29.3(26.4-32.2)$ & 163 & $9.8(7.5-12.0)$ & 1466 & $100(\mathrm{~N} / \mathrm{A})$ \\
\hline
\end{tabular}

${ }^{\mathrm{a}}$ Age adjusted to 2012 NHIS diabetes population.

bDoes not meet CKD criteria based on eGFR or albuminuria.

'Sum of rows and columns may deviate due to rounding.

${ }^{\mathrm{d} C e l l}$ frequency suppressed when count $<3$ to avoid potential identifiability and imprecision of estimates. 
Table 5 Age $\geq 65$ years: eGFR (MDRD) and UACR category prevalence of CKD in T2DM ${ }^{a}$

\begin{tabular}{|c|c|c|c|c|c|c|c|c|}
\hline \multirow{3}{*}{$\begin{array}{l}\text { GFR category, } \\
\mathrm{ml} / \mathrm{min} / 1.73 \mathrm{~m}^{2} \text { (MDRD) }\end{array}$} & \multicolumn{8}{|c|}{ Albuminuria category, $\mathrm{mg} / \mathrm{g}$} \\
\hline & \multicolumn{2}{|r|}{$<30$} & \multicolumn{2}{|r|}{$30-300$} & \multicolumn{2}{|c|}{$>300$} & \multicolumn{2}{|r|}{ Row $^{c}$} \\
\hline & $\mathrm{N}$ & $\%(95 \% \mathrm{Cl})$ & $\mathrm{N}$ & $\%(95 \% \mathrm{Cl})$ & $\mathrm{N}$ & $\%(95 \% \mathrm{Cl})$ & $\mathrm{N}$ & $\%(95 \% \mathrm{Cl})$ \\
\hline $\mathrm{G} 1 \geq 90$ & $136^{\mathrm{b}}$ & $6.5(5.3-7.7)$ & 71 & $4.3(3.2-5.4)$ & 11 & $0.6(0.1-1.1)$ & 218 & $11.4(9.9-12.9)$ \\
\hline G2 60-89 & $427^{\mathrm{b}}$ & $31.7(28.7-34.8)$ & 168 & $10.1(8.1-12.1)$ & 46 & $2.5(1.6-3.5)$ & 641 & $44.4(40.8-48.0)$ \\
\hline G3a 45-59 & 205 & $15.8(13.4-18.2)$ & 116 & $7.9(6.2-9.7)$ & 37 & $2.4(1.3-3.4)$ & 358 & $26.1(22.9-29.3)$ \\
\hline G3b 30-44 & 72 & $6.1(4.5-7.7)$ & 66 & $4.3(3.1-5.5)$ & 31 & $2.1(1.0-3.3)$ & 169 & $12.5(10.3-14.8)$ \\
\hline G4 15-29 & 14 & $0.8(0.4-1.3)$ & 27 & $2.6(1.3-3.9)$ & 28 & $2.0(0.9-3.1)$ & 69 & $5.4(3.9-6.9)$ \\
\hline $\mathrm{G} 5<15$ & d & $0.0(0.0-0.0)$ & d & $0.0(0.0-0.0)$ & 10 & $0.2(0.0-0.4)$ & 11 & $0.2(0.1-0.4)$ \\
\hline Column N, \% $(95 \% \mathrm{CI})^{c}$ & 854 & $60.9(58.2-63.7)$ & 449 & $29.3(26.4-32.2)$ & 163 & $9.8(7.5-12.0)$ & 1466 & $100(\mathrm{~N} / \mathrm{A})$ \\
\hline
\end{tabular}

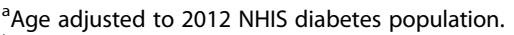

${ }^{\mathrm{b}}$ Does not meet CKD criteria based on eGFR or albuminuria.

'Sum of rows and columns may deviate due to rounding.

${ }^{d}$ Cell frequency suppressed when count $<3$ to avoid potential identifiability and imprecision of estimates.

KDOQI in 2002. The basis of the staging was to provide stage-specific treatment recommendations $[4,5]$ and allow determination of risk of progression to ESRD and mortality. Both diabetes-specific and more general treatment recommendations were given. The importance of the inclusion of the level of albuminuria in making treatment decisions was recently emphasized by the results of a meta-analysis by Lv et al. [25]. Consideration of kidney function within the categories $3 \mathrm{a}$ and $3 \mathrm{~b}$ when making diabetes- and non-diabetes-related treatment decisions has recently been emphasized $[4,26]$. Medication-related considerations include the potential for decreased ability to excrete drugs and/or their metabolites, increased sensitivity to medications (e.g. those bound to albumin), diminished tolerance of side effects, or loss of efficacy. The importance of the level of kidney function within categories $3 \mathrm{a}$ and $3 \mathrm{~b}$ is highlighted in KDIGO for metformin, where a review of its continued use is recommended when a patient transitions from category G3a to G3b [4]. Other management-related considerations at the transition of category $3 \mathrm{a}$ to $3 \mathrm{~b}$ CKD include the frequency of recommended monitoring and evaluation for evidence of metabolic bone disease [4]. This current analysis, which includes information related to the severity of albuminuria and the distribution of CKD within categories 3a and 3b, is informative to health-care providers, payers, and policy makers when making decisions on treatment choices and populationbased interventions for patients diagnosed with T2DM to potentially prevent the progression of CKD and to minimize the impact of associated complications.

The information related to the T2DM population aged $\geq$ 65 years may be relevant to those who provide care and make decisions specifically for this population, such as Medicare Part D pharmacy benefit plans. The relevance of this information in this older adult group is highlighted in the ADA 2014 standards of care [9], where there are specific considerations for AHA drug classes such as metformin, thiazolidinediones, insulin secretagogues (such as sulfonylureas), and insulin.

This study has several limitations. We focused specifically on T2DM, and therefore made an attempt to exclude NHANES participants with T1DM based on previously reported methodologies. The empirical algorithm based on age at diabetes onset and early initiation of insulin therapy may exclude younger-onset T2DM patients and include older-onset T1DM patients. The determination of the presence of kidney disease based on eGFR and albuminuria was made based on a single random sample of the laboratory values, so the chronicity of the observations could not be determined. The cause of CKD could not be determined based on the data collected in NHANES, so we could not categorize CKD according to the cause category of the new KDIGO classification. Due to the cross-sectional nature of NHANES, outcomes such as CKD progression and mortality could not be assessed.

\section{Conclusions}

This study confirms the high prevalence of CKD in T2DM, with $43.5 \%$ of individuals having evidence of CKD, and provides insights into prevalence of all CKD categories based on the new KDIGO staging system. The prevalence of more severe impairment of renal function, defined as eGFR $<45 \mathrm{ml} / \mathrm{min} / 1.73 \mathrm{~m}^{2}$, impacts $<10 \%$ of T2DM patients. This study also provides estimates of the distribution of albuminuria by severity within the categories of eGFR, providing insights into the distribution of risk categories for progression to ESRD and mortality. Additionally, this study provides estimates of the prevalence of comorbidities such as hypertension, retinopathy, and cardiac disease in people with T2DM, based on a nationally representative sample. This information may be useful to clinicians, policy makers, and entities focused on population health management. 


\section{Abbreviations}

ACE: Angiotensin-converting enzyme; ADA: American Diabetes Association; CGA: Cause of CKD, GFR category, and Albuminuria category; Cl: Confidence interval; CKD: Chronic kidney disease; CKD-EPI: Chronic Kidney Disease Epidemiology Collaboration; eGFR: Estimated glomerular filtration rate; ESRD: End-stage renal disease; IDMS: Isotope dilution mass spectrometry; KDIGO: Kidney Disease: Improving Global Outcomes; KDOQI: Kidney Disease Outcomes Quality Initiative; MDRD: Modification of Diet in Renal Disease; NHANES: National Health and Nutrition Examination Survey; NHIS: National Health Interview Survey; T1DM: Type 1 diabetes mellitus; T2DM: Type 2 diabetes mellitus; UAE: Urinary albumin excretion; UACR: Urinary albumin to creatinine ratio; US: United States.

\section{Competing interests}

RAB and MFTR are employees of Janssen Scientific Affairs, LLC, Raritan, NJ. YW and VZ are employees of Janssen Research \& Development, LLC, Titusville, NJ. All authors are stockholders of Johnson and Johnson.

\section{Authors' contributions}

RAB conceived the study concept, participated in the design of the study, participated in the interpretation of the data, and led the development of the manuscript. YW conceived the study concept, led the design of the study, helped with the statistical analysis, and helped in the development of the manuscript. VZ participated in the design of the study, performed the statistical analysis, and helped in the development of the manuscript. MFTR participated in the design of the study and the interpretation of the data, and helped in the development of the manuscript. All authors have read and approved the final manuscript and have participated in alignment with the ICMJE standards.

\section{Acknowledgements}

This analysis was funded by Janssen Scientific Affairs, LLC. Editorial support was provided by Bo Choi, PhD, of MedErgy, and Eline Hanekamp, PhD, of Excerpta Medica, and was funded by Janssen Scientific Affairs, LLC.

\section{Author details}

'Janssen Scientific Affairs, LLC, 1000 Route 202 South, Raritan, NJ 08869, USA. 2Janssen Research \& Development, LLC, Titusville, NJ, USA.

Received: 11 June 2014 Accepted: 27 June 2014

Published: 2 July 2014

\section{References}

1. Koro CE, Lee BH, Bowlin SJ: Antidiabetic medication use and prevalence of chronic kidney disease among patients with type 2 diabetes mellitus in the United States. Clin Ther 2009, 31:2608-2617.

2. U.S. Renal Data System: USRDS 2013 Annual Data Report: Atlas of Chronic Kidney Disease and End-Stage Renal Disease in the United States. Bethesda, MD: National Institutes of Health, National Institute of Diabetes and Digestive and Kidney Diseases; 2013. [http://www.usrds.org/atlas.aspx]

3. Laliberte R, Bookhart B, Vekeman F, Corral M, Duh MS, Bailey RA, Piech CT, Lefebvre P: Direct all-cause health care costs associated with chronic kidney disease in patients with diabetes and hypertension: a managed care perspective. J Manag Care Pharm 2009, 15:312-322.

4. Kidney Disease: Improving Global Outcomes (KDIGO) CKD Working Group: KDIGO 2012 clinical practice guidelines for the evaluation and management of chronic kidney disease. Kidney Int Supp/ 2013, 3(1):1-150.

5. National Kidney Foundation: K/DOQI clinical practice guidelines for chronic kidney disease: evaluation, classification, and stratification. Am J Kidney Dis 2002, 5(Suppl 1):S1-S266.

6. Go AS, Chertow GM, Fan D, McColloch CE, Hsu CY: Chronic kidney disease and the risks of death, cardiovascular events, and hospitalization. $N$ Engl J Med 2004, 351:1296-1305.

7. Gansevoort RT, Matsushita K, van der Velde M, Astor BC, Woodward M, Levey AS, de Jong PE, Coresh J, Chronic Kidney Disease Prognosis Consortium: Lower estimated GFR and higher albuminuria are associated with adverse kidney outcomes. A collaborative meta-analysis of general and high-risk population cohorts. Kidney Int 2011, 80:93-104.

8. Matsushita K, van der Velde M, Astor B, Woodward M, Levey A: Association of estimated glomerular filtration rate and albuminuria with all-cause and cardiovascular mortality in general population cohorts: a collaborative meta-analysis. Lancet 2010, 375:2073-2081.

9. American Diabetes Association: Standards of medical care in diabetes-2014. Diabetes Care 2014, 37(suppl 1):S5-S80.

10. NHANES homepage. [http://www.cdc.gov/nchs/nhanes.htm]

11. Dodd AH, Colby MS, Boye KS, Fahlman C, Kim S, Briefel RR: Treatment approach and $\mathrm{HbA} 1 \mathrm{c}$ control among US adults with type 2 diabetes: NHANES 1999-2004. Curr Med Res Opin 2009, 25:1605-1613.

12. Reinstatler L, Qi YP, Williamson RS, Garn JV, Oakley GP: Association of biochemical $B_{12}$ deficiency with metformin therapy and vitamin $B_{12}$ supplements: the National Health and Nutrition Examination Survey, 1999-2006. Diabetes Care 2012, 35:327-333.

13. Doggen $K$, Nobels F, Scheen AJ, Van Crombrugge P, Van Casteren V, Mathieu C: Cardiovascular risk factors and complications associated with albuminuria and impaired renal function in insulin-treated diabetes. J Diabetes Complications 2013, 27:370-375.

14. Levey AS, Stevens LA, Schmid CH, Zhang Y, Castro AF, Feldman HI, Kusek JW, Eggers P, Van Lente F, Greene T, Coresh J, CKD-EPI (Chronic Kidney Disease Epidemiology Collaboration): A new equation to estimate glomerular filtration rate. Ann Intern Med 2009, 150:604-612.

15. Levey AS, Coresh J, Green T, Stevens LA, Zhang YL, Hendriksen S, Kusek JW, Van Lente F, Chronic Kidney Disease Epidemiology Collaboration: Using standardized serum creatinine values in the Modification of Diet in Renal Disease Study equation for estimating glomerular filtration rate. Ann Intern Med 2006, 145:247-254.

16. Specifying weighting parameters. [http://www.cdc.gov/nchs/tutorials/ nhanes/SurveyDesign/Weighting/intro.htm]

17. Age standardization and population counts. [http://www.cdc.gov/ nchs/tutorials/nhanes/NHANESAnalyses/AgeStandardization/age standardization_intro.htm]

18. National health interview survey. [http://www.cdc.gov/nchs/nhis/ nhis_2010_data_release.htm]

19. Plantinga LC, Crews DC, Coresh J, Miller ER, Saran R, Yee J, Hedgeman E, Pavkov M, Eberhardt MS, Williams DE, Powe NR: Prevalence of chronic kidney disease in US adults with undiagnosed diabetes or prediabetes. Clin J Am Soc Nephrol 2010, 5:673-682.

20. Coresh J, Selvin E, Stevens LA, Manzi J, Kusek JW, Eggers P, Van Lente F, Levey AS: Prevalence of chronic kidney disease in the United States. JAMA 2007, 298:2038-2047.

21. Stevens LA, Schmid CH, Greene T, Zhang YL, Beck GJ, Froissart M, Hamm LL, Mauer M, Navis GH, Steffes MW, Eggers PW, Coresh J, Levey AS: Comparative performance of the CKD Epidemiology Collaboration (CKD-EPI) and the Modification of Diet in Renal Disease (MDRD) equations for estimating GFR levels above $60 \mathrm{~mL} / \mathrm{min} / 1.73 \mathrm{~m}^{2}$. Am J Kidney Dis 2010, 56:486-495.

22. Matsushita K, Mahmoodi BK, Woodward M, Embeson JR, Jafar TH, Jee SH, Polkinghorne KR, Shankar A, Smith DH, Tonelli M, Warnock DG, Wen CP, Gansevoort RT, Hemmelgarn BR, Levey AS: Comparison of risk prediction using the CKD-EPI equation and the MDRD study equation for estimated glomerular filtration rate. JAMA 2012, 307:1941-1951.

23. National Kidney Disease Education Program website. [http://nkdep.nih. gov/lab-evaluation/gfr/estimating.shtml]

24. Incidence of end-stage renal disease among persons with diabetes United States, 1990-2002. [http://www.cdc.gov/mmwr/preview/ mmwrhtml/mm5443a2.htm]

25. Lv J, Ehteshami P, Sarnak MJ, Tighiouart H, Jun M, Ninomiya T, Foote C, Rodgers A, Zhang H, Wang H, Strippoli GFM, Perkovic V: Effects of intensive blood pressure lowering on the progression of chronic kidney disease: a systematic review and meta-analysis. CMAJ 2013, 185:949-957.

26. Anouts P, Bolignano D, Nistor I, Bilo H, Gnudi L, Heaf J, van Biesen W: Glucose-lowering drugs in patients with chronic kidney disease: a narrative review on pharmacokinetic properties. [http://ndt.oxfordjournals. org/content/early/2013/12/08/ndt.gft462.long]

\section{doi:10.1186/1756-0500-7-415}

Cite this article as: Bailey et al: Chronic kidney disease in US adults with type 2 diabetes: an updated national estimate of prevalence based on Kidney Disease: Improving Global Outcomes (KDIGO) staging. BMC Research Notes 2014 7:415. 